\title{
Intracellular Toxic Advanced Glycation End-Products Promote the Production of Reactive Oxygen Species in HepG2 Cells
}

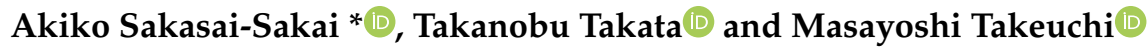 \\ Department of Advanced Medicine, Medical Research Institute, Kanazawa Medical University, 1-1 Daigaku, \\ Uchinada, Kahoku, Ishikawa 920-0293, Japan; takajjjj@kanazawa-med.ac.jp (T.T.); \\ takeuchi@kanazawa-med.ac.jp (M.T.) \\ * Correspondence: asakasai@kanazawa-med.ac.jp; Tel.: +81-76-286-2211
}

Received: 15 June 2020; Accepted: 6 July 2020; Published: 9 July 2020

check for updates

\begin{abstract}
Hepatocyte cell death is a key process in the pathogenesis of nonalcoholic steatohepatitis (NASH). However, the factors responsible for and mechanisms underlying NASH-related cell death have not yet been elucidated in detail. We herein investigated the effects of intracellular glyceraldehyde (GA)-derived advanced glycation end-products (AGEs), named toxic AGEs (TAGE), on the production of reactive oxygen species (ROS), which have been implicated in the pathogenesis of NASH. Cell death related to intracellular TAGE accumulation was eliminated in the hepatocyte carcinoma cell line HepG2 by the antioxidant effects of N-acetyl-L-cysteine. The intracellular accumulation of TAGE increased ROS production and the expression of Nrf2, including its downstream gene. These results suggest that ROS are produced in association with the accumulation of TAGE and are a direct trigger for cell death. We also investigated the factors responsible for these increases in ROS. Catalase activity did not decrease with the accumulation of TAGE, while mitochondrial membrane depolarization was enhanced in cells treated with GA. These results indicate that TAGE play an important role in mitochondrial abnormalities and increases in ROS production, both of which are characteristic features of NASH. The suppression of TAGE accumulation has potential as a new therapeutic target in the progression of NASH.
\end{abstract}

Keywords: nonalcoholic fatty liver disease (NAFLD); nonalcoholic steatohepatitis (NASH); advanced glycation end-products (AGEs); glyceraldehyde (GA); glyceraldehyde-derived AGEs; toxic AGEs (TAGE); reactive oxygen species (ROS); hepatocytes

\section{Introduction}

Due to global increases in the prevalence of metabolic syndrome (MetS), nonalcoholic fatty liver disease (NAFLD), a phenotype of MetS, is now the most common liver disorder worldwide. Nonalcoholic steatohepatitis (NASH) is a severe form of NAFLD and its importance is being increasingly recognized because of its potential to progress to fibrosis or cirrhosis [1,2]. The pathogenesis of NAFLD, particularly NASH, overlaps with those of a number of lifestyle-related diseases, including obesity, diabetic insulin resistance, and dyslipidemia [1,2]. Furthermore, a spectrum of parallel hits, including oxidative stress, insulin resistance, genetic and epigenetic mechanisms, environmental elements, cytokines, nutritional factors, and gut microflora, have been used to explain the progression of NAFLD to NASH ("multiple parallel hits") [3].

An excessive intake of sucrose and/or high fructose corn syrup (HFCS) is also considered to be one of the causes of NASH [4]. The chronic ingestion of excess amounts of sugar and HFCS increases the level of advanced glycation end-products (AGEs) in the body. Under hyperglycemic states, AGEs are 
generated through a non-enzymatic glycation reaction (the Maillard reaction) between the ketone or aldehyde groups of sugars and the amino groups of proteins. The AGEs generated depend on the sugars reacted with. AGEs derived from glyceraldehyde (GA), a metabolic intermediate of glucose and fructose, are particularly cytotoxic and referred to as toxic AGEs (TAGE). TAGE accumulation has been associated with NASH, infertility, cancer, dementia, schizophrenia, and cardiovascular disease [5-15]. TAGE are expected to mainly accumulate in hepatocytes because excess fructose is mostly metabolized by the liver. A previous study reported that TAGE accumulated in livers of patients with NASH, and to a lesser extent in those with simple steatosis [5]. TAGE accumulation has been shown to induce cytotoxicity in hepatocytes [16,17]. AGEs form intra- and inter-protein crosslinking structures [18]. Various proteins, including caspase-3, an apoptosis-executing factor, and Hsp70, which is involved in chaperone activity, were found to be modified by TAGE, and these TAGE modifications resulted in the loss of protein function and contributed to cell death [16,17]. These findings suggest that intracellular TAGE play a role in hepatocyte cell damage and the development of NASH [19-21].

Reactive oxygen species (ROS) induce cell damage, and a strong correlation has been reported between the degree of oxidative stress and severity of NASH [22-24]. However, cells possess nuclear factor erythroid 2-related factor 2 (Nrf2) as a defense mechanism against oxidative and inflammatory stress. Under stress conditions, Nrf2 is activated, resulting in the up-regulation of genes encoding key protective enzymes, such as quinone oxide reductase 1 (NQO1), heme oxygenase-1 (HO-1), glutathione S-transferase (GST), aldo-keto reductase, $\gamma$-glutamylcysteine ligase, thioredoxin, and thioredoxin reductase [25]. Furthermore, the activation of Nrf2 exerts potent anti-inflammatory effects and plays an important role in the resolution of inflammation. The expression of the Nrf2 strongly correlated with the development of NASH induced by a high-fat diet [26]. The expression levels of HO-1, a downstream gene of Nrf2, were also found to be elevated in NASH patients [27]. The factors that promote oxidative stress in NASH patients include an increase in ROS production and/or a decrease in antioxidant factors. Regarding the relationship between TAGE and ROS production, extracellular TAGE have been shown to promote the production of ROS by binding to receptor for AGEs (RAGE) on hepatocytes and hepatic stellate cells, which enhances inflammation and fibrosis, which are characteristic of NASH [28,29]. However, it currently remains unclear whether intracellular TAGE are involved in ROS production. Since TAGE derived from the intermediates of glucose and fructose metabolism are produced inside hepatocyte cells, the mechanisms underlying intracellular damage need to be elucidated in more detail in order to attenuate TAGE-induced damage. A previous study on the relationship between intracellular damage and ROS production in the progression of NASH revealed a decrease in antioxidant proteins, including catalase, and an increase in mitochondrial abnormalities $[24,30]$, possibly due to abnormalities in these constituent proteins. These findings prompted us to hypothesize that TAGE modifications inhibit the functions of these antioxidants and/or mitochondria, thereby contributing to the production of ROS and onset of NASH.

In the present study, we examined the relationship between intracellular TAGE accumulation and ROS production in HepG2 cells and the factors responsible for ROS production to clarify the mechanisms by which the accumulation of TAGE contributes to the pathogenesis of NASH.

\section{Results}

\subsection{HepG2 Cell Death Associated with the Intracellular Accumulation of TAGE Is Rescued by NAC}

Excess amounts of glucose and fructose are mainly metabolized in the liver. GA is produced as an intermediate of this metabolic process and has the potential to react with proteins to form TAGE. The intracellular accumulation of TAGE has been implicated in HepG2 cell death (Figure 1a,b) [17]. We confirmed this cytotoxicity in human primary hepatocytes as well as HepG2 cells (Figure 1c) [17]. A pretreatment with aminoguanidine (AG), an inhibitor of the formation of AGEs, abrogated the intracellular formation of TAGE and cell death by GA (Figure 1d,e) [17]. TAGE-modified proteins are considered to contribute to cellular dysfunction due to the loss of their functions; however, it currently 
remains unclear whether they are a direct trigger for cell death. We hypothesized that ROS trigger TAGE-accumulated hepatocyte cell death. If this is the case, antioxidants may be able to prevent this type of cell death. NAC, an inhibitor of ROS, suppressed GA-induced HepG2 and human primary hepatocytes death, as well as HepG2 cell death induced by $\mathrm{H}_{2} \mathrm{O}_{2}$. (Figure 1a,c and Figure S1). Furthermore, this inhibitory effect of NAC did not attenuate the formation of TAGE (Figure 1b), indicating that ROS are responsible for TAGE-accumulated cell death.

(a)

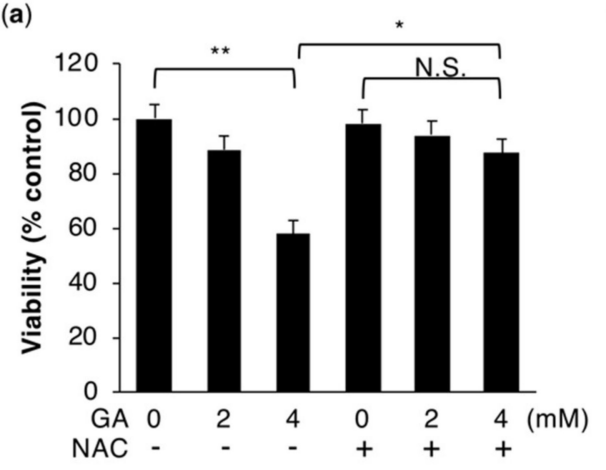

(c)

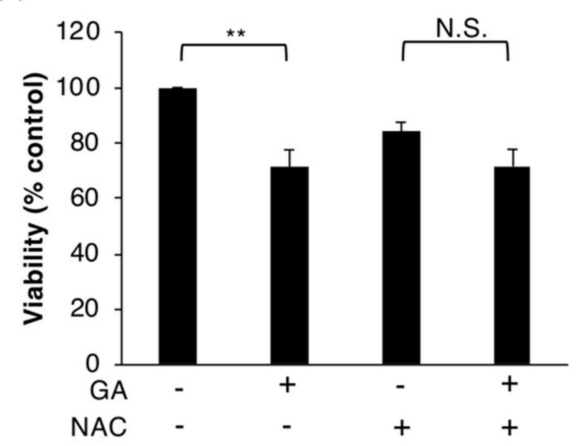

(e)

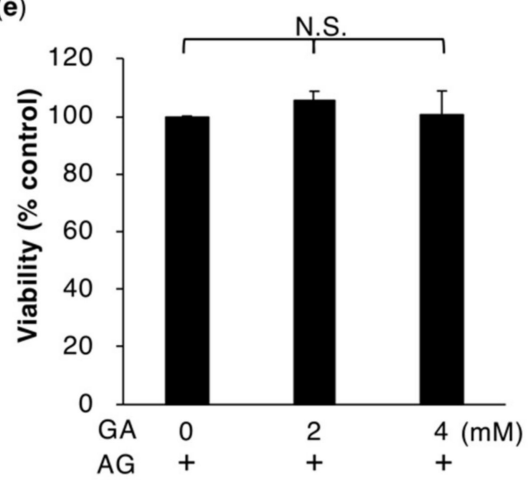

(b)

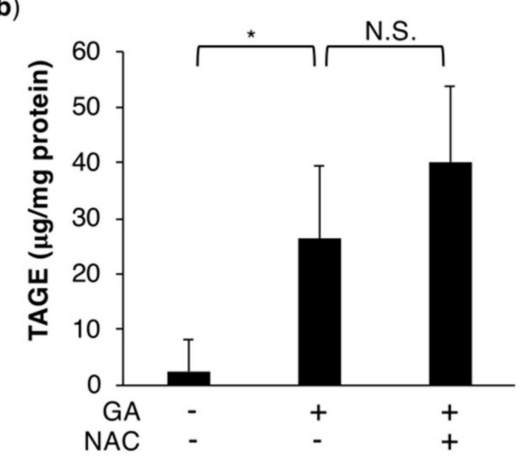

(d)

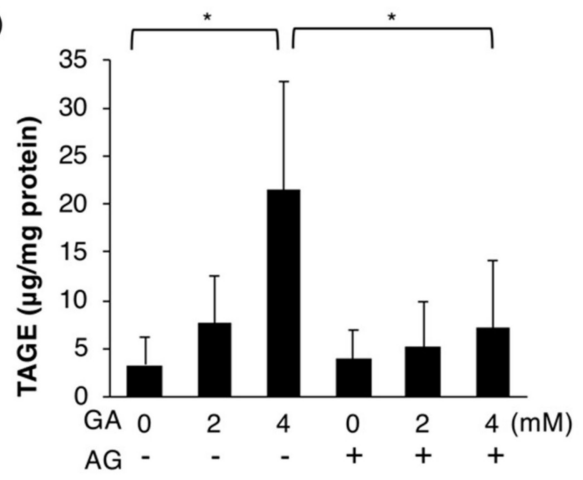

Figure 1. TAGE accumulation-induced hepatocytes death is rescued by the antioxidant NAC. (a,c) Cell viability was measured using the CellTiter-Glo luminescent cell viability assay $(n=3)$. HepG2 cells (a) were treated with 0,2 , or $4 \mathrm{mM} \mathrm{GA}$ without or with $5 \mathrm{mM} \mathrm{NAC}$ for $24 \mathrm{~h}$. Primary hepatocytes (c) were treated with 0 or $4 \mathrm{mM} \mathrm{GA}$ without or with $5 \mathrm{mM} \mathrm{NAC}$ for $24 \mathrm{~h}$. (b,d) Slot blotting was performed to measure intracellular TAGE. (b) Cell extracts were prepared from HepG2 cells treated with 0 or $4 \mathrm{mM}$ GA without or with $5 \mathrm{mM} \mathrm{NAC}$ for $24 \mathrm{~h}(n=4)$. (d) Cell extracts were prepared from HepG2 cells treated with 0 or $16 \mathrm{mM}$ AG for $2 \mathrm{~h}$ followed by 0,2 , or $4 \mathrm{mM} \mathrm{GA}$ for $24 \mathrm{~h}(n=3)$. (e) HepG2 cells were treated with $16 \mathrm{mM}$ AG for $2 \mathrm{~h}$ followed by 0,2 , or $4 \mathrm{mM} \mathrm{GA}$ for $24 \mathrm{~h}$ and cell viability was then measured. Results are mean \pm S.D. ${ }^{*} p<0.05,{ }^{* *} p<0.01$ and N.S. (Not significant) based on a one-way ANOVA followed by Tukey's test (a-d). 


\subsection{Intracellular Accumulation of TAGE Induces ROS Production in Hepatocyte Cells}

GA-induced hepatocyte cell death was rescued by NAC, suggesting that ROS production is a trigger for TAGE-accumulated cell death (Figure 1). Moreover, previous studies demonstrated that elevated levels of ROS represent a key mechanism for the progression of NASH [22-24]. We investigated intracellular ROS accumulation in cells treated with GA (Figure 2). Intracellular ROS were detected using fluorescent probes that react with the intracellular hydroxyl radical ( $\left.\mathrm{HO}^{*}\right)$ and hypochlorous acid $(\mathrm{HClO})$. The GA treatment and positive control hydrogen peroxide $\left(\mathrm{H}_{2} \mathrm{O}_{2}\right)$ both induced the production of ROS in HepG2 cells (Figure 2a,b). We also confirmed this ROS production in human primary hepatocytes as well as HepG2 cells (Figure S2). On the other hand, GA-induced ROS production was suppressed by the pretreatment with AG in HepG2 cells (Figure S3). These results indicated that TAGE accumulation was associated with ROS production.

(a)
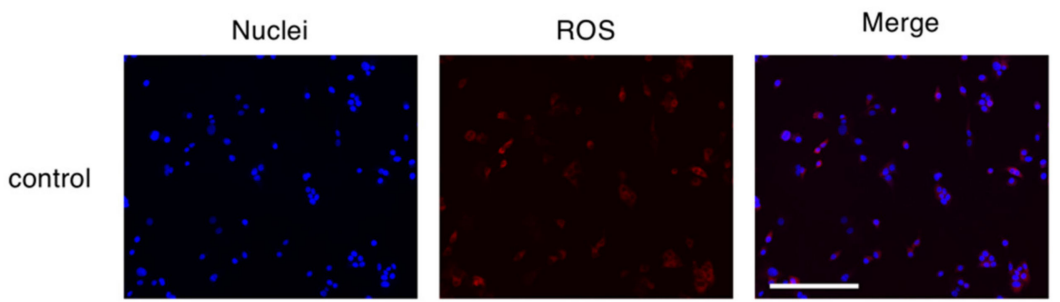

GA
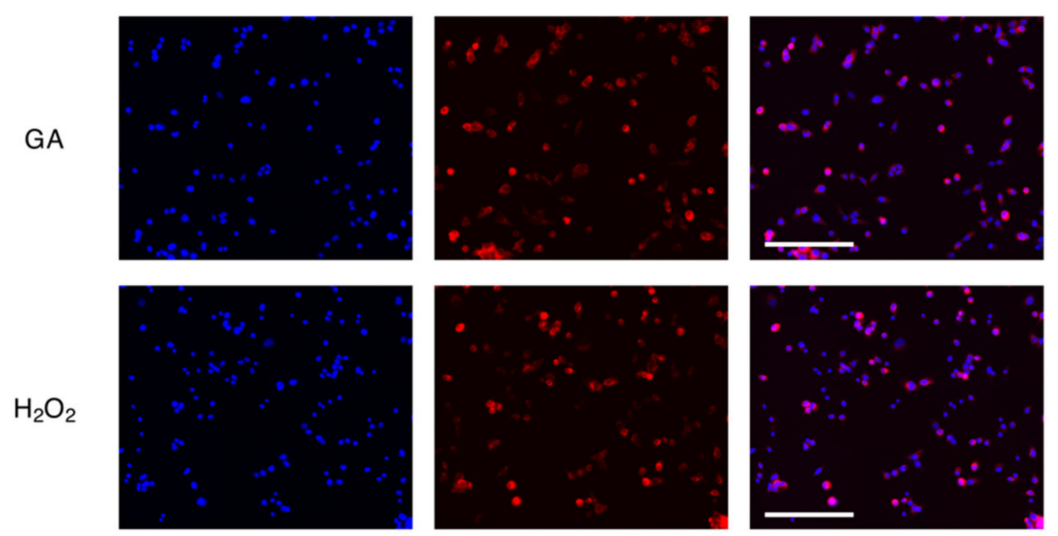

(b)

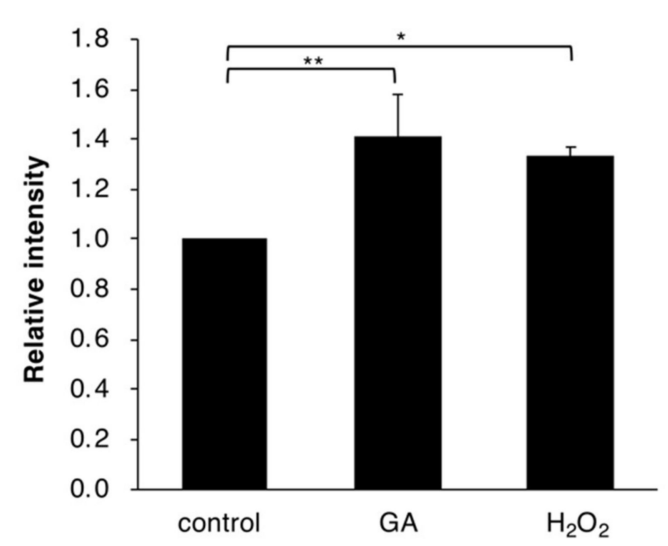

Figure 2. ROS accumulation in HepG2 cells treated with GA. (a) Representative fluorescence images of nuclei (Hoechst 33342; blue fluorescence) and ROS formation (OxiORANGE; red fluorescent) in HepG2 cells. Magnification for the figure is $\times 20$. Cells were prepared from HepG2 cells treated with 0 or $4 \mathrm{mM} \mathrm{GA}$ or $1 \mathrm{mM} \mathrm{H}_{2} \mathrm{O}_{2}$ for $6 \mathrm{~h}$. Experiments were repeated in triplicate with similar results. Scale bar $=200 \mu \mathrm{m}$. (b) The relative fluorescence intensity of HepG2 cells in each group. Results are mean \pm S.D. ${ }^{*} p<0.05$ and ${ }^{* *} p<0.01(n=3)$ based on a one-way ANOVA followed by Dunnett's test. 


\subsection{The GA Treatment Triggers Intracellular ROS Stress Responses}

Excess ROS induce cellular dysfunction. However, cells have evolved an antioxidant defense system that includes Nrf2, a transcriptional factor for the induction of a variety of detoxification enzymes. Therefore, we investigated whether GA-induced ROS production enhanced Nrf2 transcriptional activity. The results obtained showed that the mRNA expression levels of Nrf2 were increased by GA (Figure 3a and Figure S4a). Moreover, HO-1, downstream of Nrf2, was increased by GA and $\mathrm{H}_{2} \mathrm{O}_{2}$ (Figure $3 \mathrm{~b}$ and Figure S4b). These results suggested that GA induced the production of ROS in cells as well as ROS stress responses.

(a)

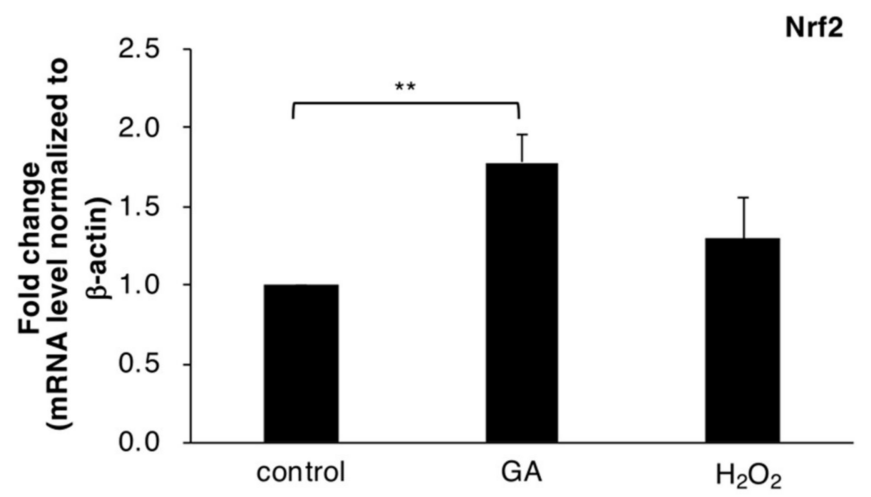

(b)

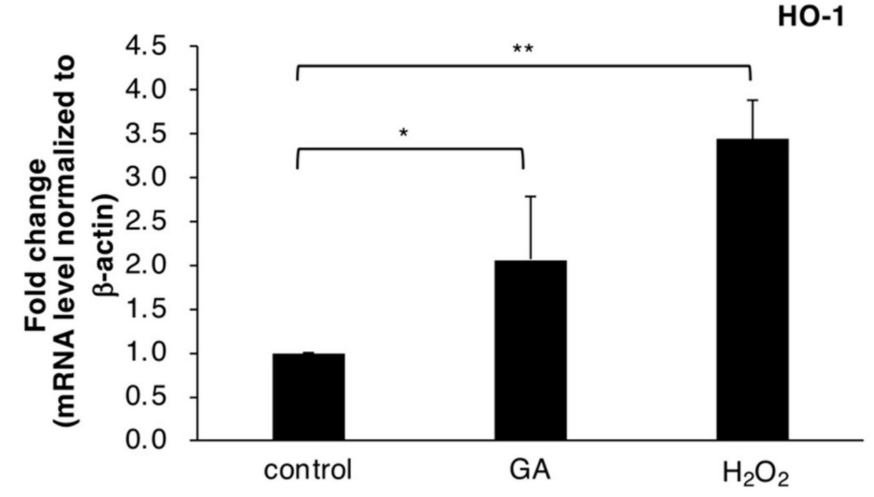

Figure 3. Quantitative real-time PCR demonstrated that Nrf2 (a) and HO-1 (b) expression levels were increased by GA in HepG2 cells after a treatment with 0 or $4 \mathrm{mM} \mathrm{GA}$ or $1 \mathrm{mM} \mathrm{H}_{2} \mathrm{O}_{2}$ for $6 \mathrm{~h}$. $\mathrm{H}_{2} \mathrm{O}_{2}$ was employed as a positive control. Normalized gene expression levels were given as a ratio between the mean value for the target gene and that for $\beta$-actin in each sample. Results are mean \pm S.D. ${ }^{*} p<0.05$ and ${ }^{* *} p<0.01(n \geq 3)$ based on a one-way ANOVA followed by Dunnett's test.

\subsection{Catalase Dysfunction is Not Responsible for GA-Induced ROS Production}

One of the contributing factors to ROS production in cells is reduced antioxidant activity. Decreases in antioxidant molecules, including SOD, catalase, glutathione, and glutathione S-transferase, have been shown to correlate with the severity of $\mathrm{NASH}$ [30]. The present results revealed that $\mathrm{HO}$ or $\mathrm{HClO}$ were generated by HepG2 cells treated with GA (Figure 2). $\mathrm{HO}^{\prime}$ and $\mathrm{HClO}$ are both formed by the conversion of $\mathrm{H}_{2} \mathrm{O}_{2}$ through the Fenton reaction or myeloperoxidase. We assumed that catalase, which is abundantly expressed in the liver and decomposes $\mathrm{H}_{2} \mathrm{O}_{2}$ to water and molecular oxygen, lost its protein function due to TAGE modifications. Therefore, the activity of catalase in GA-treated HepG2 cells was assessed. An analysis of the catalase protein by Western blotting (WB) showed no significant difference in the monomer band of catalase with or without the drug treatment (Figure 4a,b). However, slower migrating bands of catalase were observed with the GA treatment, and less with the control or AG treatment. This slower migrating band in GA-treated cells was inhibited by the 
additional treatment with AG (Figure 4a,c). These bands were suggested to be TAGE-modified catalase multimers because glycated proteins form crosslinking structures on adjacent or within domains of a protein. We investigated whether TAGE-modified catalase lost its enzyme activity. 3-Amino-1,2,4-triazole (3-AT), known as an inhibitor of catalase, treatment decreased catalase activity in HepG2 cells, indicating that the inactivation of catalase is detectable using HepG2 cells, despite its strong catalase activity (Figure S5). However, a decrease in catalase activity was not observed following the GA treatment (Figure 4d). These results demonstrated that the increased intracellular production of ROS in cells treated with GA was not due to the inactivation of catalase.

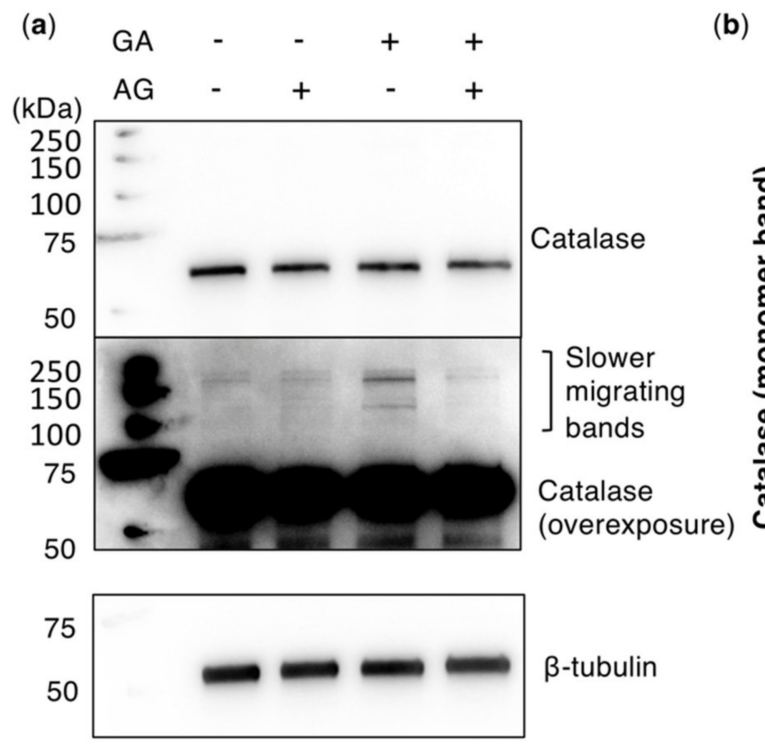

(b)

(c)

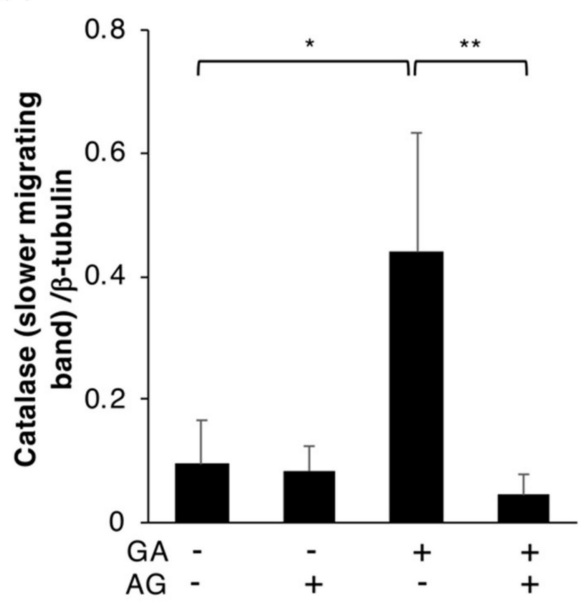

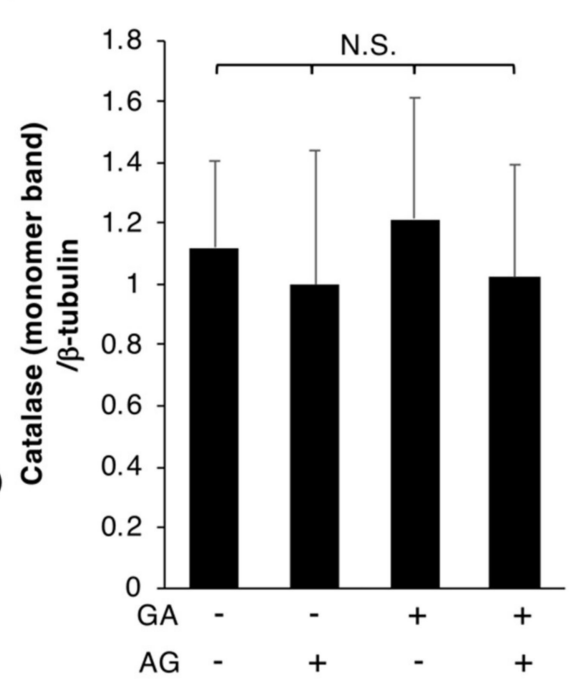

(d)

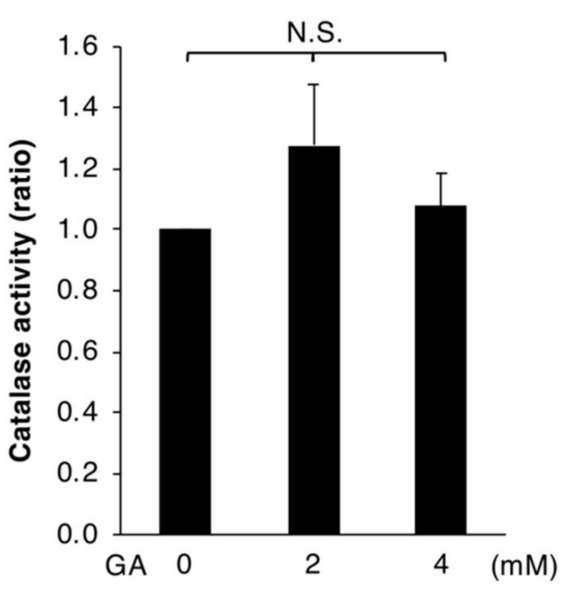

Figure 4. Catalase activity is not suppressed in GA-treated HepG2 cells. (a) Western blotting was performed to analyze the effects of the GA treatment on catalase. Cell extracts were prepared from HepG 2 cells treated with 0 or $16 \mathrm{mM}$ AG for $2 \mathrm{~h}$ followed by 0 or $4 \mathrm{mM} \mathrm{GA}$ for $6 \mathrm{~h}$. $\beta$-tubulin was used as the loading control. Experiments were repeated in triplicate with similar results. Full-length blots are shown in Figure S6. (b,c) A densitometric analysis was used to calculate the relative ratio of catalase (monomer band) $/ \beta$-tubulin (b) or catalase (slower migrating band) $/ \beta$-tubulin (c). (d) Catalase-dependent activity was measured using $\mathrm{H}_{2} \mathrm{O}_{2}$ as the substrate. Cells were prepared from HepG2 cells treated with 0,2 , or 4 mM GA for 6 h. Results are mean \pm S.D. ${ }^{*} p<0.05,{ }^{* *} p<0.01$ and N.S. (Not significant) $(n=3)$ based on a one-way ANOVA followed by Tukey's test. 


\subsection{The GA Treatment Induces an Abnormal Mitochondrial Membrane Potential}

Mitochondrial damage leads to the intracellular production of ROS. The collapse of the mitochondrial membrane potential is a critical step in the mitochondrion-mediated oxidative stress pathway $[24,31,32]$. We examined the effects of GA on mitochondrial membrane depolarization by staining with the mitochondrial potential-sensitive dye JC-1, which emits green fluorescence when the mitochondrial membrane potential is disrupted. When the mitochondrial membrane potential is normal, red fluorescence is emitted. The red fluorescence of JC- 1 was observed in control and drug-treated cells (Figure 5a). Carbonylcyanide p-trifluoromethoxyphenylhydrazone (FCCP), known as a potent uncoupler of oxidative phosphorylation able to collapse mitochondrial membrane potential, treatment increased in the green fluorescence of JC-1 (Figure S7). A marked increase in the green fluorescence of JC-1 was noted in GA-treated cells, indicating a reduced mitochondrial membrane potential (Figure 5a,b). However, green fluorescence was suppressed in GA-treated cells pretreated with AG (Figure 5a,b and Figure S7).

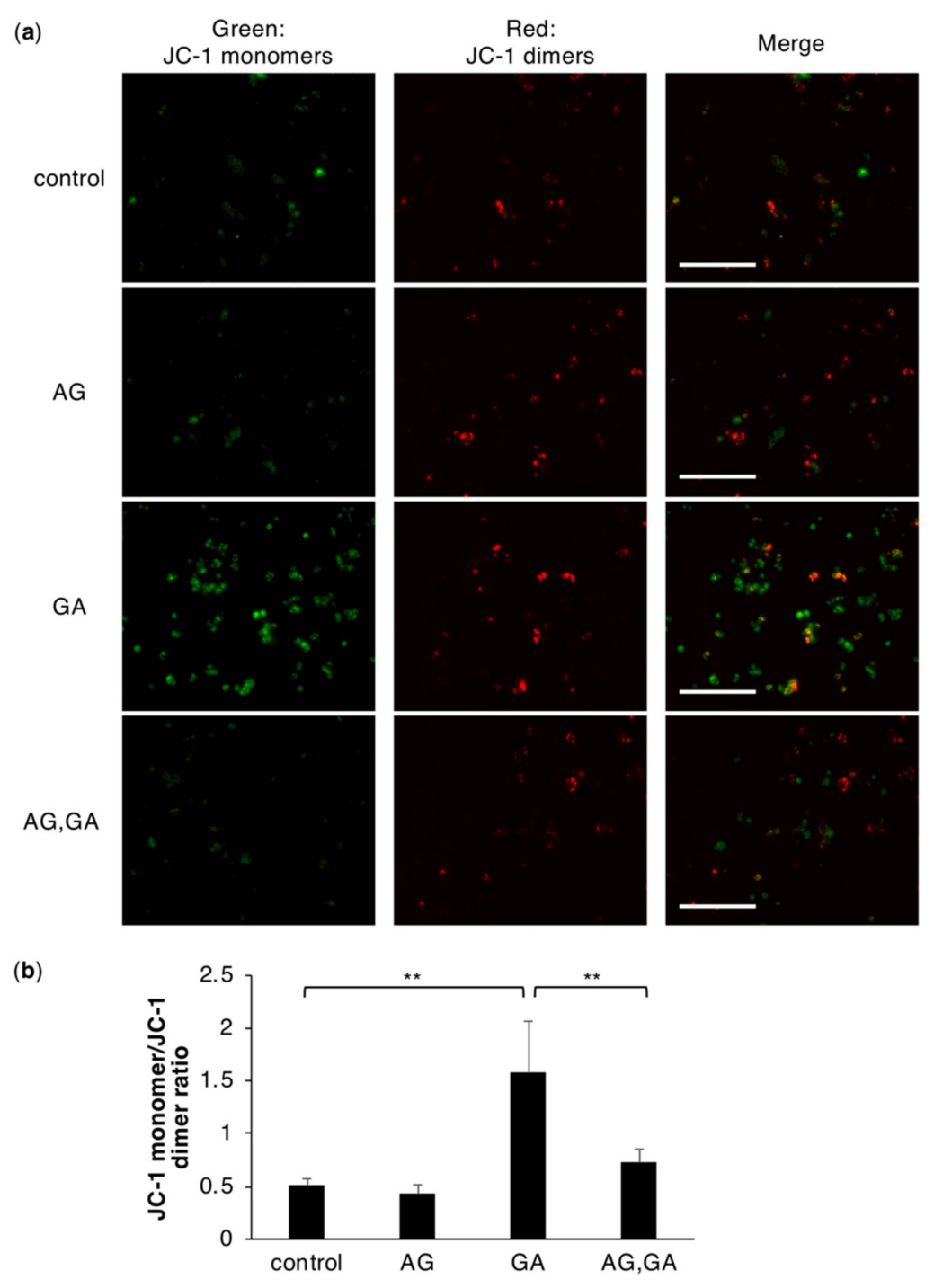

Figure 5. Mitochondrial membrane depolarization in HepG2 cells treated with GA. (a) Depolarization of the mitochondrial membrane potential was observed (the magnification for the figure is $\times 20$ ) after cells were treated with 0 or $16 \mathrm{mM} \mathrm{AG}$ for $2 \mathrm{~h}$ followed by 0 or $4 \mathrm{mM} \mathrm{GA}$ for $6 \mathrm{~h}$. Scale bar $=200 \mu \mathrm{m}$. (b) The relative fluorescence intensities of JC-1 monomer/JC-1 dimer. Results are mean \pm S.D. ${ }^{* *} p<0.01$ $(n=3)$ based on a one-way ANOVA followed by Tukey's test. 


\section{Discussion}

The "multiple parallel hits" hypothesis has been proposed for the pathogenesis of NASH and reportedly includes obesity, insulin resistance, dyslipidemia, and excessive intakes of sucrose and HFCS $[1,2,4]$. These factors induce intracellular ROS stress, which enhances inflammation in NASH [22-24]. AGEs produced in a hyperglycemic state are also considered to be involved in the development of NASH $[4,5,19-21,33]$. Among AGEs, TAGE are highly cytotoxic and have been shown to induce intra- and extra-cellular damage to hepatocytes $[16,17,28,33,34]$. To suppress the cytotoxicity of TAGE, the mechanisms by which they damage cells need to be elucidated in more detail. In the present study, we extracellularly added GA, a precursor of TAGE, at the millimolar level to investigate the impact of intracellular TAGE accumulation. Previous studies reported that fructose is a major source of GA, and fructose-fed mice exhibited a NASH-like pathology [35]. Even at the cellular level, the accumulation of TAGE-modified proteins was observed in hepatocytes grown in high fructose medium for 5 days [36]. The accumulation of these proteins was also observed in hepatocytes treated with $4 \mathrm{mM}$ GA for $6 \mathrm{~h}$ [36]. Therefore, a treatment with GA in the millimolar order is considered to be the optimum concentration for short-term experiments on cells in dishes. Furthermore, HepG2 cells were mainly used to analyze the effect of TAGE toxicity in the present study. HepG2 is a hepatocyte carcinoma cell line that has a different phenotype from normal hepatocytes. However, even though their metabolic pathways differ, particularly glucose, the direct treatment of cells with GA allows us to analyze the effects of TAGE on HepG2 cells without any metabolic pathway because of non-enzymatic formation of TAGE. Moreover, the results for cytotoxicity and ROS production by GA treatment in human primary hepatocytes were similar to HepG2 cells. Thus, we consider the results observed in HepG2 cells to represent one approach to monitoring the effects of TAGE toxicity in NASH pathology.

Intracellular GA has the potential to react with essential proteins for cell maintenance, resulting in a loss of cell viability. We previously identified caspase-3, an apoptosis-executing factor, as a target of TAGE modifications, which consequently lost its enzyme activity and has been implicated in the necrosis of hepatocytes [17]. If cellular damage exceeds cytoprotection, cell death, such as apoptosis and necrosis, occurs. Therefore, some factors responsible for the induction of necrotic cell death may be related to TAGE modifications in caspase-3. ROS are cytotoxic factors that play a central role in cell signaling as well as in the regulation of the main pathways of cell death. Furthermore, a strong correlation has been reported between the pathogenesis of NASH and ROS stress [22-24], suggesting that ROS induce hepatocyte cell death. Thus, we hypothesized that ROS initiate hepatocyte cell death due to TAGE accumulation.

In the present study, we revealed that hepatocyte cell death due to intracellular TAGE accumulation was suppressed by a treatment with NAC (Figure 1), which is a precursor of glutathione, the most powerful antioxidant. NAC has been shown to exert therapeutic effects against NASH [37,38]. In addition to the effects of antioxidants on cell survival, we confirmed that GA induced the production of ROS in cells (Figure 2 and Figures S2 and S3). However, cells possess an antioxidant defense system against ROS. Nrf2, a transcription factor, is one component of this defense system and regulates the transcription of antioxidant proteins [39]. The relationships between NAFLD and NASH, and Nrf2 are well known. Nrf2-deficient mice show the rapid onset and progression of NASH [40]. HO-1 is present downstream of Nrf2 and suppresses inflammation. The expression of HO-1 was previously reported in NASH patients [27]. The present results also demonstrated that the mRNA expression levels of Nrf2 and HO-1 were increased in cells treated with GA, indicating that GA promoted the production of ROS and activated Nrf2-regulated stress response factors (Figure 3 and Figure S4). A previous study showed that a treatment with GA increased the mRNA expression levels of the inflammation marker C-reactive protein (CRP) in the hepatocyte cell line Hep3B [16]. Furthermore, ROS were found to up-regulate the expression of CRP in hepatocytes [41], suggesting that GA-induced ROS initiate an inflammatory response that is a feature of NASH.

Intracellular oxidative stress may be caused by decreases in antioxidant activity or mitochondrial abnormalities. Decreases in antioxidant molecules, including SOD, catalase, glutathione, 
and glutathione S-transferase, have been correlated with the severity of NASH [30]. Furthermore, AGE-modified proteins lose their functions due to the formation of intra- and inter-protein crosslinking structures. These findings prompted us to hypothesize that TAGE-modified antioxidant proteins lose their enzyme activity and, thus, are unable to inhibit increases in ROS. In the present study, we used fluorescent probes that react with $\mathrm{HO}^{\circ}$ and $\mathrm{HClO}$. These radicals are produced by $\mathrm{H}_{2} \mathrm{O}_{2}$ through myeloperoxidase and the Fenton reaction. We assumed that $\mathrm{H}_{2} \mathrm{O}_{2}$ levels were elevated in TAGE-accumulated HepG2 cells. Catalase, which decomposes $\mathrm{H}_{2} \mathrm{O}_{2}$, was examined as a candidate antioxidant protein for TAGE modifications. We found faint and slower migrating catalase protein bands, indicating TAGE modifications, in GA-treated HepG2 cells (Figure 4). However, no changes were observed in its antioxidant activity, which suggested that decreases in the antioxidant activity of catalase were not responsible for the increases observed in the intracellular production of ROS in cells treated with GA. We also examined mitochondria, which are a major source of ROS in various mammalian cells [31,32,42]. We analyzed the mitochondrial transmembrane potential, an essential parameter of mitochondrial function, as an indicator of cell health [43]. An abnormal mitochondrial membrane potential was noted in cells treated with GA and was suppressed by the AG pretreatment (Figure 5). Therefore, these results suggested that the mitochondrial membrane potential abnormality was associated with TAGE modifications to intracellular proteins, which induced the production of ROS. Intracellular ROS production induced by the treatment of GA to cells has also been reported in rat pancreatic islets [44]. On the other hand, Takahashi et al. showed that elevations in ROS production in rat islets were mediated by a non-mitochondrial pathway, which differed from the present results obtained using hepatocytes. Differences in the mechanisms of ROS production among these cell types, which are both affected by high glucose levels, are inferred to have distinct pathogenic mechanisms of disease caused by an excess intake of sugar.

Further studies on the TAGE-modified target proteins involved in maintaining the mitochondrial membrane potential and the mechanisms underlying the exclusion of abnormal mitochondria by TAGE accumulation, such as mitophagy, are needed. Nevertheless, the present results demonstrated for the first time that ROS are a direct trigger of cell death due to intracellular TAGE accumulation. This study also provides novel insights into the role of TAGE in the pathogenesis of NASH.

\section{Materials and Methods}

\subsection{Reagents and Antibodies}

Glyceraldehyde (GA; catalog number: 17014-81) was purchased from Nacalai Tesque (Kyoto, Japan). N-acetyl-L-cysteine (NAC; catalog number: A9165) and 3-amino-1,2,4-triazole (3-AT; catalog number: A8056) were obtained from Sigma-Aldrich (St. Louis, MI, USA). Aminoguanidine (AG; catalog number: 328-26432) and hydrogen peroxide $\left(\mathrm{H}_{2} \mathrm{O}_{2}\right.$; catalog number: 081-04215) were from FUJIFILM Wako Pure Chemical Corporation (Osaka, Japan). The following antibodies were used in the present study: anti-catalase (Abcam, Cambridge, UK, catalog number: ab209211) and anti- $\beta$-tubulin antibodies (FUJIFILM Wako Pure Chemical Corporation, catalog number: 014-25041). An anti-TAGE antibody was prepared and purified as described previously [45].

\subsection{Cell Culture}

The human HCC cell line, HepG2 (ECACC No. 85011430), was purchased from ECACC and maintained in low glucose Dulbecco's modified Eagle's medium (DMEM; Sigma-Aldrich, catalog number: D6046) supplemented with 10\% fetal bovine serum (FBS; Sigma-Aldrich), $100 \mathrm{U} / \mathrm{mL}$ penicillin, and $100 \mu \mathrm{g} / \mathrm{mL}$ streptomycin (FUJIFILM Wako Pure Chemical Corporation, catalog number: 168-23191). Primary hepatocytes from a human liver were purchased from Kurabo Industries Ltd. (Osaka, Japan, catalog number: HHCPC-4M) and maintained in KLC seeding medium (catalog number: KLC-SM). These cells were maintained at $37^{\circ} \mathrm{C}$ in a humidified incubator with $5 \% \mathrm{CO}_{2}$. Cells were plated at a density of $3.0 \times 10^{4}$ cells $/ \mathrm{cm}^{2}$ for HepG2 cells or $4.0 \times 10^{4}$ cells $/ \mathrm{cm}^{2}$ for primary hepatocytes. HepG2 
cells were treated with reagents including GA in 2\% FBS/DMEM in order to prevent the formation of extracellular AGEs.

\subsection{Cell Viability}

The CellTiter-Glo luminescent cell viability assay was performed on each sample according to the manufacturer's instructions (Promega, Madison, WI, USA, catalog number: G7570). Briefly, cells were plated in triplicate onto opaque 96-well plates. After an incubation for $24 \mathrm{~h}$, cells were treated with 0 or $4 \mathrm{mM} \mathrm{GA}$ for $24 \mathrm{~h}, 0$ or $5 \mathrm{mM}$ NAC for $24 \mathrm{~h}, 0$ or $16 \mathrm{mM}$ AG for $26 \mathrm{~h}$. Cells were then incubated for 10 min with CellTiter-Glo reagent, and luminescence was measured using a 96-well plate reader (GloMax-96 microplate luminometer, Promega). Background luminescence was measured in medium without cells and subtracted from experimental values. Neither GA, NAC, nor AG exerted suppressive effects on luciferase activity in this assay.

\subsection{Slot Blotting}

Slot blotting was performed to detect the total amount of TAGE in floating and adherent hepatocyte cell extracts treated with the indicated drug treatments. This analysis was performed as previously described [17].

\subsection{ROS Detection and Measurement.}

OxiORANGE (Goryo Chemical, Sapporo, Japan, catalog number: GC3004-01) was employed for the intracellular detection of ROS. HepG2 cells were cultured in a Glass Bottom Dish $35 \mathrm{~mm}$ (Matsunami Glass Ind., Ltd., Osaka, Japan), catalog number: D11141H) for $24 \mathrm{~h}$ and then stained with OxiORANGE and Hoechst 33342 (Invitrogen, Carlsbad, CA, USA, catalog number: H3570), for nuclei staining, at $37^{\circ} \mathrm{C}$ for $20 \mathrm{~min}$ after washing with PBS. These cells were washed with PBS and then treated with the indicated reagent for $6 \mathrm{~h}$. Cells were washed with PBS and fixed with $4 \%$ PFA (Nacalai Tesque, catalog number: 09154-85) at $4{ }^{\circ} \mathrm{C}$ for $20 \mathrm{~min}$. Immediately after washing with PBS, intracellularly induced ROS were observed under the BZ-X700 microscope (Keyence, Osaka, Japan).

A 96-well plate reader was used to measure ROS fluorescence. HepG2 cells were cultured in a 4-cm dish instead of a 96-well plate because cells were prone to detachment during the manipulation, and the following steps were performed. After an incubation for $24 \mathrm{~h}$, cells were stained with OxiORANGE for $20 \mathrm{~min}$ after washing with PBS. These cells were washed and treated with the indicated reagent for $6 \mathrm{~h}$. Cells were washed with PBS and trypsinized. A total of $2.0 \times 10^{4}$ cells were plated in triplicate onto white opaque 96-well plates and fluorescence (excitation: $544 \mathrm{~nm}$, emission: $590 \mathrm{~nm}$ ) was then measured using a 96-well plate reader (Fluoroscan Ascent plate reader; Thermo Fisher Scientific, Waltham, MA, USA).

\subsection{RNA Extraction and Quantitative Real-Time Reverse Transcription-PCR ( $q R T-P C R$ )}

Total RNAs from HepG2 cells were extracted using the RNeasy Micro kit (Qiagen, Hilden, Germany, catalog number: 74004). A qRT-PCR analysis was conducted using the One Step TB Green PrimeScript RT-PCR Kit (Takara BIO, Shiga, Japan, catalog number: RR086A) with the QuantStudio 12k flex Real-Time PCR system (Life Technologies, Carlsbad, CA, USA) according to the manufacturers' instructions. One nanogram of RNA was used in the reaction mixture. Primer sequence details were as follows: $\beta$-actin forward, $5^{\prime}$-AGAGCTACGAGCTGCCTGAC- $3^{\prime}$ and reverse, 5' -AGCACTGTGTTGGCGTACAG-3' , Nrf2 forward, 5' -TTCAGCCAGCCCAGCACATC-3' and reverse, 5'-CGTAGCCGAAGAAACCTCATTGTC-3' , HO-1 forward, 5' -AAGACTGCGTTCCTGCTCAA-3' and reverse, 5'-GGGCAGAATCTTGCACTTTGT-3'. These primers for human were obtained from Eurofins (Tokyo, Japan). Relative quantification was performed using the delta-delta ct method, and data were normalized using $\beta$-actin as an internal standard. A dissociation curve analysis was conducted for each experiment. The efficiency of the primers was as follows: $\beta$-actin 87\%, Nrf2 90\%, HO-1 92\%. All experiments were amplified in three different wells and run more than three times. 


\subsection{Western Blotting}

HepG2 cells were washed with PBS three times and lysed in sodium dodecyl sulfate (SDS) sample buffer (60 mM Tris- $\mathrm{HCl}$ (pH 6.8), 2\% SDS, 5\% glycerol, 5\% 2-mercaptoethanol, and bromophenol blue) followed by heating at $95{ }^{\circ} \mathrm{C}$ for $5 \mathrm{~min}$. Equal amounts of cell extracts were resolved by SDS polyacrylamide gel electrophoresis (SDS-PAGE) with Any kD Mini-PROTEAN TGX Precast Protein Gels (Bio-Rad, Hercules, CA, USA, catalog number: 4569035). Proteins were transferred onto PVDF membranes. Membranes were then blocked at room temperature for $1 \mathrm{~h}$ using $5 \%$ skimmed milk in PBS-T, washed twice with PBS-T, and incubated with the anti-catalase antibody (1:2000) at $4{ }^{\circ} \mathrm{C}$ overnight. Washing and the incubation with the secondary antibody were performed as described in the slot blotting section. Immunoreactive proteins were detected with Chemi-Lumi One Super (Nacalai Tesque, catalog number: 02230) using a luminescent image analyzer (Fusion; Vilber-Lourmat, Marne-la-Vallée, France). Equivalent sample loading was confirmed by stripping membranes, followed by blotting with the anti- $\beta$-tubulin antibody $(1: 30,000)$. Densitometric analyses of protein bands in the Western blots were done using Image J software from NIH (Bethesda, MA, USA). Relative band intensities for catalase or catalase (monomer) was normalized with the intensities of the corresponding $\beta$-tubulin.

\subsection{Measurement of Catalase Activity}

Catalase activity was measured to assess the antioxidant activity of cells according to the protocol described by Iwase et al. [46]. Briefly, cells were harvested, trypsinized, and adjusted to $2.5 \times 10^{6}$ cells/1 mL PBS in a test tube. The cell suspension was then mixed with $100 \mu \mathrm{L}$ of $1 \%$ Triton X-100 and $100 \mu \mathrm{L}$ of $30 \%(w / v) \mathrm{H}_{2} \mathrm{O}_{2}$ and incubated at $25^{\circ} \mathrm{C}$ for $15 \mathrm{~min}$. The height of $\mathrm{O}_{2}$-forming foam produced by the breakdown of $\mathrm{H}_{2} \mathrm{O}_{2}$ by catalase was measured to indicate the enzymatic activity of catalase.

\subsection{Analysis of the Mitochondrial Membrane Potential}

The mitochondrial membrane potential was observed using the JC-1 Mitochondrial Membrane Potential Assay Kit (Abcam, catalog number: ab113850) following the manufacturer's instructions. Briefly, cells were washed once with $1 \times$ Dilution buffer and then incubated with $20 \mu \mathrm{M} \mathrm{JC}-1$ at $37^{\circ} \mathrm{C}$ for $10 \mathrm{~min}$. Cells were washed with $1 \times$ Dilution buffer twice, and then incubated with the indicated reagent for the desired time period in $2 \%$ FBS/DMEM without phenol red. These cells were observed under the BZ-X700 microscope (Keyence). These fluorescence were analyzed with the Image J software from NIH.

\subsection{Statistical Analysis}

We used a one-way ANOVA followed by Tukey's or Dunnett's test for comparisons of intergroup differences using Stat Flex 6.0 software (Artech, Osaka, Japan) and representative graphs have been prepared. Experiments were repeated at least three times and data are presented as the mean \pm S.D. Significant differences are presented as $p$-values $* p<0.05,{ }^{* *} p<0.01$, and N.S. (Not significant) in the figures and corresponding figure legends.

Supplementary Materials: Supplementary Materials may be found at http://www.mdpi.com/1422-0067/21/14/ 4861/s1.

Author Contributions: All authors substantially contributed to the preparation of this manuscript. A.S.-S. drafted and wrote the manuscript. T.T. and M.T. edited and critically reviewed the manuscript. All authors discussed and confirmed the final manuscript. All authors have read and agreed to the published version of the manuscript.

Funding: This work was supported by JSPS KAKENHI Grant Numbers JP18K11003 \& JP16H01811.

Acknowledgments: The authors would like to thank Takayuki Ikeda and Makoto Taniguchi for their technical assistance with the experiment.

Conflicts of Interest: The authors declare no conflicts of interest. 


\section{Abbreviations}

$\begin{array}{ll}\text { AG } & \text { Aminoguanidine } \\ \text { AGEs } & \text { Advanced glycation end-products } \\ \text { CRP } & \text { C-reactive protein } \\ \text { GA } & \text { Glyceraldehyde } \\ \mathrm{HClO} & \text { Hypochlorous acid } \\ \mathrm{HFCS} & \text { High fructose corn syrup } \\ \mathrm{HO} & \text { Hydroxyl radical } \\ \mathrm{H}_{2} \mathrm{O}_{2} & \text { Hydrogen peroxide } \\ \text { MetS } & \text { Metabolic syndrome } \\ \text { NAC } & \text { N-acetyl-L-cysteine } \\ \text { NAFLD } & \text { Nonalcoholic fatty liver disease } \\ \text { NASH } & \text { Nonalcoholic steatohepatitis } \\ \text { RAGE } & \text { Receptor for AGEs } \\ \text { ROS } & \text { Reactive oxygen species } \\ \text { TAGE } & \text { Toxic AGEs } \\ \text { WB } & \text { Western blotting }\end{array}$

\section{References}

1. Polyzos, S.A.; Kountouras, J.; Mantzoros, C.S. Obesity and nonalcoholic fatty liver disease: From pathophysiology to therapeutics. Metabolism 2019, 92, 82-97. [CrossRef] [PubMed]

2. Katsiki, N.; Mikhailidis, D.P.; Mantzoros, C.S. Non-alcoholic fatty liver disease and dyslipidemia: An update. Metabolism 2016, 65, 1109-1123. [CrossRef] [PubMed]

3. Takaki, A.; Kawai, D.; Yamamoto, K. Multiple hits, including oxidative stress, as pathogenesis and treatment target in non-alcoholic steatohepatitis (NASH). Int. J. Mol. Sci. 2013, 14, 20704-20728. [CrossRef] [PubMed]

4. Jensen, T.; Abdelmalek, M.F.; Sullivan, S.; Nadeau, K.J.; Green, M.; Roncal, C.; Nakagawa, T.; Kuwabara, M.; Sato, Y.; Kang, D.H.; et al. Fructose and sugar: A major mediator of non-alcoholic fatty liver disease. J. Hepatol. 2018, 68, 1063-1075. [CrossRef]

5. Hyogo, H.; Yamagishi, S.I.; Iwamoto, K.; Arihiro, K.; Takeuchi, M.; Sato, T.; Ochi, H.; Nonaka, M.; Nabeshima, Y.; Inoue, M.; et al. Elevated levels of serum advanced glycation end products in patients with non-alcoholic steatohepatitis. J. Gastroenterol. Hepatol. 2007, 22, 1112-1119. [CrossRef]

6. Jinno, M.; Takeuchi, M.; Watanabe, A.; Teruya, K.; Hirohama, J.; Eguchi, N.; Miyazaki, A. Advanced glycation end-products accumulation compromises embryonic development and achievement of pregnancy by assisted reproductive technology. Hum. Reprod. 2011, 26, 604-610. [CrossRef]

7. Kong, S.Y.; Takeuchi, M.; Hyogo, H.; Mckeown-eyssen, G.; Yamagishi, S.; Chayama, K.; Brien, P.J.O.; Ferrari, P.; Overvad, K.; Olsen, A.; et al. The association between glyceraldehyde-derived advanced glycation end-products and colorectal cancer risk. Cancer Epidem. Biomaker. Prev. 2015, 24, 1855-1863. [CrossRef]

8. Choei, H.; Sasaki, N.; Takeuchi, M.; Yoshida, T.; Ukai, W.; Yamagishi, S.I.; Kikuchi, S.; Saito, T. Glyceraldehyde-derived advanced glycation end products in Alzheimer's disease. Acta Neuropathol. 2004, 108, 189-193. [CrossRef] [PubMed]

9. Koriyama, Y.; Furukawa, A.; Muramatsu, M.; Takino, J.; Takeuchi, M. Glyceraldehyde caused Alzheimer's disease-like alterations in diagnostic marker levels in SH-SY5Y human neuroblastoma cells. Sci. Rep. 2015, 5, 13313. [CrossRef]

10. Takeda, M.; Ohnuma, T.; Takeuchi, M.; Katsuta, N.; Maeshima, H.; Takebayashi, Y.; Higa, M.; Nakamura, T.; Nishimon, S.; Sannohe, T.; et al. Altered serum glyceraldehyde-derived advanced glycation end product (AGE) and soluble AGE receptor levels indicate carbonyl stress in patients with schizophrenia. Neurosci. Lett. 2015, 593, 51-55. [CrossRef]

11. Tahara, N.; Yamagishi, S.I.; Takeuchi, M.; Honda, A.; Tahara, A.; Nitta, Y.; Kodama, N.; Mizoguchi, M.; Kaida, H.; Ishibashi, M.; et al. Positive association between serum level of glyceraldehyde-derived advanced glycation end products and vascular inflammation evaluated by [18F]fluorodeoxyglucose positron emission tomography. Diabetes Care 2012, 35, 2618-2625. [CrossRef] [PubMed] 
12. Ueda, S.; Yamagishi, S.; Matsui, T.; Noda, Y.; Ueda, S.; Jinnouchi, Y.; Sasaki, K.; Takeuchi, M.; Imaizumi, T. Serum levels of advanced glycation end products (AGEs) are inversely associated with the number and migratory activity of circulating endothelial progenitor cells in apparently healthy subjects. Cardiovasc. Ther. 2012, 30, 249-254. [CrossRef] [PubMed]

13. Kajikawa, M.; Nakashima, A.; Fujimura, N.; Maruhashi, T.; Iwamoto, Y.; Iwamoto, A.; Matsumoto, T.; Oda, N.; Hidaka, T.; Kihara, Y.; et al. Ratio of serum levels of AGEs to soluble form of RAGE is a predictor of endothelial function. Diabetes Care 2015, 38, 119-125. [CrossRef]

14. Shimomura, M.; Oyama, J.; Takeuchi, M.; Shibata, Y.; Yamamoto, Y.; Kawasaki, T.; Komoda, H.; Kodama, K.; Sakuma, M.; Toyoda, S.; et al. Acute effects of statin on reduction of angiopoietin-like 2 and glyceraldehyde-derived advanced glycation end-products levels in patients with acute myocardial infarction: A message from SAMIT (Statin for Acute Myocardial Infarction Trial). Heart Vessel. 2016, 31, 1583-1589. [CrossRef]

15. Takata, T.; Sakasai-Sakai, A.; Ueda, T.; Takeuchi, M. Intracellular toxic advanced glycation end-products in cardiomyocytes may cause cardiovascular disease. Sci. Rep. 2019, 9, 2121. [CrossRef]

16. Takino, J.; Kobayashi, Y.; Takeuchi, M. The formation of intracellular glyceraldehyde-derived advanced glycation end-products and cytotoxicity. J. Gastroenterol. 2010, 45, 646-655. [CrossRef]

17. Sakasai-Sakai, A.; Takata, T.; Takino, J.; Takeuchi, M. Impact of intracellular glyceraldehyde-derived advanced glycation end-products on human hepatocyte cell death. Sci. Rep. 2017, 7, 14282. [CrossRef] [PubMed]

18. Vasan, S.; Foiles, P.; Founds, H. Therapeutic potential of breakers of advanced glycation end product-protein crosslinks. Arch. Biochem. Biophys. 2003, 419, 89-96. [CrossRef]

19. Sakasai-Sakai, A.; Takata, T.; Takino, J.; Takeuchi, M. The relevance of toxic AGEs (TAGE) cytotoxicity to NASH pathogenesis: A mini-review. Nutrients 2019, 11, 462. [CrossRef] [PubMed]

20. Takeuchi, M.; Sakasai-Sakai, A.; Takata, T.; Ueda, T.; Takino, J.; Tsutsumi, M.; Hyogo, H.; Yamagishi, S. Serum levels of toxic AGEs (TAGE) may be a promising novel biomarker in development and progression of NASH. Med. Hypotheses 2015, 84, 490-493. [CrossRef] [PubMed]

21. Takeuchi, M.; Takino, J.; Sakasai-Sakai, A.; Takata, T.; Tsutsumi, M. Toxic AGE (TAGE) theory for the pathophysiology of the onset/progression of NAFLD and ALD. Nutrients 2017, 9, 634. [CrossRef] [PubMed]

22. Sumida, Y.; Nakashima, T.; Yoh, T.; Furutani, M.; Hirohama, A.; Kakisaka, Y.; Nakajima, Y.; Ishikawa, H.; Mitsuyoshi, H.; Okanoue, T.; et al. Serum thioredoxin levels as a predictor of steatohepatitis in patients with nonalcoholic fatty liver disease. J. Hepatol. 2003, 38, 32-38. [CrossRef]

23. Sumida, Y.; Niki, E.; Naito, Y.; Yoshikawa, T. Involvement of free radicals and oxidative stress in NAFLD/NASH. Free Radic. Res. 2013, 47, 869-880. [CrossRef]

24. Masarone, M.; Rosato, V.; Dallio, M.; Gravina, A.G.; Aglitti, A.; Loguercio, C.; Federico, A.; Persico, M. Role of oxidative stress in pathophysiology of nonalcoholic fatty liver disease. Oxid. Med. Cell. Longev. 2018, 2018, 1-14. [CrossRef]

25. Vasileva, L.V.; Savova, M.S.; Amirova, K.M.; Dinkova-Kostova, A.T.; Georgiev, M.I. Obesity and NRF2-mediated cytoprotection: Where is the missing link? Pharmacol. Res. 2020, 156, 104760. [CrossRef]

26. Wang, C.; Cui, Y.; Li, C.; Zhang, Y.; Xu, S.; Li, X.; Li, H.; Zhang, X. Nrf2 deletion causes "benign" simple steatosis to develop into nonalcoholic steatohepatitis in mice fed a high-fat diet. Lipids Health Dis. 2013, 12, 1-8. [CrossRef]

27. Malaguarnera, L.; Madeddu, R.; Palio, E.; Arena, N.; Malaguarnera, M. Heme oxygenase-1 levels and oxidative stress-related parameters in non-alcoholic fatty liver disease patients. J. Hepatol. 2005, 42, 585-591. [CrossRef]

28. Yoshida, T.; Yamagishi, S.; Nakamura, K.; Matsui, T.; Imaizumi, T.; Takeuchi, M.; Ueno, T.; Sata, M. Pigment epithelium-derived factor (PEDF) inhibits advanced glycation end product (AGE)-induced C-reactive protein expression in hepatoma cells by suppressing Rac-1 activation. FEBS Lett. 2006, 580, 2788-2796. [CrossRef]

29. Iwamoto, K.; Kanno, K.; Hyogo, H.; Yamagishi, S.; Takeuchi, M.; Tazuma, S.; Chayama, K. Advanced glycation end products enhance the proliferation and activation of hepatic stellate cells. J. Gastroenterol. 2008, 43, 298-304. [CrossRef]

30. Videla, L.A.; Rodrigo, R.; Orellana, M.; Fernandez, V.; Tapia, G.; Quiñones, L.; Varela, N.; Contreras, J.; Lazarte, R.; Csendes, A.; et al. Oxidative stress-related parameters in the liver of non-alcoholic fatty liver disease patients. Clin. Sci. 2004, 106, 261-268. [CrossRef] 
31. Guo, C.Y.; Sun, L.; Chen, X.P.; Zhang, D.S. Oxidative stress, mitochondrial damage and neurodegenerative diseases. Neural Regen. Res. 2013, 8, 2003-2014. [CrossRef] [PubMed]

32. Brennan, J.P.; Southworth, R.; Medina, R.A.; Davidson, S.M.; Duchen, M.R.; Shattock, M.J. Mitochondrial uncoupling, with low concentration FCCP, induces ROS-dependent cardioprotection independent of KATP channel activation. Cardiovasc. Res. 2006, 72, 313-321. [CrossRef] [PubMed]

33. Fernando, D.H.; Forbes, J.M.; Angus, P.W.; Herath, C.B. Development and progression of non-alcoholic fatty liver disease: The role of advanced glycation end products. Int. J. Mol. Sci. 2019, 20, 5037. [CrossRef]

34. Takino, J.; Yamagishi, S.; Takeuchi, M. Glycer-AGEs-RAGE signaling enhances the angiogenic potential of hepatocellular carcinoma by upregulating VEGF expression. World J. Gastroenterol. 2012, 18, 1781-1788. [CrossRef]

35. Kawasaki, T.; Igarashi, K.; Koeda, T.; Sugimoto, K.; Nakagawa, K.; Hayashi, S.; Yamaji, R.; Inui, H.; Fukusato, T.; Yamanouchi, T. Rats fed fructose-enriched diets have characteristics of nonalcoholic hepatic steatosis. J. Nutr. 2009, 139, 2067-2071. [CrossRef]

36. Takino, J.; Nagamine, K.; Takeuchi, M.; Hori, T. In vitro identification of nonalcoholic fatty liver disease-related protein hnRNPM. World J. Gastroenterol. 2015, 21, 1784-1793. [CrossRef]

37. Thong-Ngam, D.; Samuhasaneeto, S.; Kulaputana, O.; Klaikeaw, N. N-acetylcysteine attenuates oxidative stress and liver pathology in rats with non-alcoholic steatohepatitis. World J. Gastroenterol. 2007, 13, 5127-5132. [CrossRef]

38. De Andrade, K.Q.; Moura, F.A.; Dos Santos, J.M.; De Araújo, O.R.P.; de Farias Santos, J.C.; Goulart, M.O.F. Oxidative stress and inflammation in hepatic diseases: Therapeutic possibilities of $\mathrm{N}$-acetylcysteine. Int. J. Mol. Sci. 2015, 16, 30269-30308. [CrossRef]

39. Bataille, A.M.; Manautou, J.E. Nrf2 a potential target for new therapeutics in liver disease. Clin. Pharmacol. Ther. 2012, 92, 340-348. [CrossRef]

40. Chowdhry, S.; Nazmy, M.H.; Meakin, P.J.; Dinkova-Kostova, A.T.; Walsh, S.V.; Tsujita, T.; Dillon, J.F.; Ashford, M.L.J.; Hayes, J.D. Loss of Nrf2 markedly exacerbates nonalcoholic steatohepatitis. Free Radic. Biol. Med. 2010, 48, 357-371. [CrossRef] [PubMed]

41. Zhao, J.; Liu, J.; Pang, X.; Wang, S.; Wu, D.; Zhang, X.; Feng, L. Angiotensin II induces C-reactive protein expression via AT1-ROS-MAPK-NF-кB signal pathway in hepatocytes. Cell. Physiol. Biochem. 2013, 32, 569-580. [CrossRef] [PubMed]

42. Murphy, M.P. How mitochondria produce reactive oxygen species. Biochem. J. 2009, 417, 1-13. [CrossRef]

43. Sivandzade, F.; Bhalerao, A.; Cucullo, L. Analysis of the mitochondrial membrane potential using the cationic JC-1 dye as a sensitive fluorescent probe. Bio-Protocol 2019, 9, 3128. [CrossRef]

44. Takahashi, H.; Tran, P.O.; LeRoy, E.; Harmon, J.S.; Tanaka, Y.; Robertson, R.P. D-Glyceraldehyde causes production of intracellular peroxide in pancreatic islets, oxidative stress, and defective beta cell function via non-mitochondrial pathways. J. Biol. Chem. 2004, 279, 37316-37323. [CrossRef] [PubMed]

45. Takeuchi, M.; Makita, Z.; Bucala, R.; Suzuki, T.; Koike, T.; Kameda, Y. Immunological evidence that non-carboxymethyllysine advanced glycation end-products are produced from short chain sugars and dicarbonyl compounds in vivo. Mol. Med. 2000, 6, 114-125. [CrossRef]

46. Iwase, T.; Tajima, A.; Sugimoto, S.; Okuda, K.I.; Hironaka, I.; Kamata, Y.; Takada, K.; Mizunoe, Y. A simple assay for measuring catalase activity: A visual approach. Sci. Rep. 2013, 3, 3081. [CrossRef]

(C) 2020 by the authors. Licensee MDPI, Basel, Switzerland. This article is an open access article distributed under the terms and conditions of the Creative Commons Attribution (CC BY) license (http://creativecommons.org/licenses/by/4.0/). 